\title{
Spatial variation in the recruitment of benthic assemblages to artificial substrata
}

\author{
Michael J. Rule*, Stephen D. A. Smith \\ School of Environmental Science and Natural Resources Management, University of New England, \\ National Marine Science Centre, PO Box J321, Coffs Harbour, New South Wales 2450, Australia
}

\begin{abstract}
Artificial substrata have repeatedly been advocated as useful tools for monitoring environmental change; however, the spatial scales of recruitment to these substrata are mostly unknown. Nests of nylon pan scourers were used to examine variation in the recruitment of marine benthic assemblages over a range of spatial scales (metres, 10s of metres, 100s of metres, kilometres), within the Solitary Islands Marine Park (SIMP), NSW, Australia. Using a nested design, artificial substratum units (ASUs) were anchored to rocky reef for a period of $5 \mathrm{mo}$, at a depth of 6 to $8 \mathrm{~m}$, at 2 island sites. Data were subjected to both univariate and multivariate analyses to determine the similarity of assemblages between all hierarchical levels. Artificial substrata were colonised predominantly by motile fauna. Large-scale patterns of recruitment were obvious, with samples from NW Solitary Island numerically dominated by the bivalve Hiatella australis, and samples from North Solitary Island by the amphipod Mallacoota euroka. Significant differences in the mean abundance of individual faunal groups (amphipods, bivalves, polychaetes, decapods) were identified over all spatial scales. Multivariate analyses revealed the structure of recruiting assemblages varied over all scales although differences at the smallest spatial scale were uncommon. The results highlight the importance of variation over both small and large spatial scales for assemblages of motile fauna recruiting to artificial substrata, and suggest that this variation needs to be considered when conducting experiments with these types of artificial substrata.
\end{abstract}

KEY WORDS: Spatial scale $\cdot$ Recruitment $\cdot$ Motile invertebrates $\cdot$ Artificial substrata Resale or republication not permitted without written consent of the publisher

\section{INTRODUCTION}

Marine benthic communities encompass a hierarchy of structure (Farnsworth \& Ellison 1996) and thus form a complex mosaic of small patches with differing species composition nested within larger patches (Kay \& Keough 1981, Morrisey et al. 1992, Downes \& Keough 1998). Larval dispersal, and the subsequent settlement and recruitment of invertebrates, provides the link between these patches. The composition of benthic assemblages can be strongly influenced by spatial variation in the initial settlement and recruitment of individuals (Downes \& Keough 1998, Glasby 1998). Regional variation in recruitment is known to result from broad-scale hydrodynamic processes (Eckman 1990) and shoreline configurations (Bertness et al. 1996), while local variation most often results from small-scale habitat heterogeneity (Bourget et al. 1994), biotic interactions (i.e. post-settlement mortality, Osman \& Whitlatch 1996, Hunt \& Scheibling 1997, Smith \& Whitman 1999; facilitation, Pawlik et al. 1991), larval supply (Underwood \& Fairweather 1989, Bertness et al. 1996) and larval behaviour (Rodriguez et al. 1993). Without prior knowledge of the distribution of assemblages, the outcomes of sampling programs may be confounded by variation over smaller spatial scales than those being investigated (Andrew \& Mapstone 1987, Wiens 1989, Morrisey et al. 1992, Glasby 1998). This has implications for both the management of natural populations and for environmental impact studies, and highlights the necessity of designing experiments appropriate to natural scales of variation (Andrew \& Mapstone 1987, Farnsworth \& Ellison 1996). 
In areas where habitat heterogeneity is high, comparisons between sites, and even between samples, may be further confounded due to a lack of replicable habitat. Small variations in the morphology of natural habitats may significantly influence the structure of associated communities (Gunnill 1982, Edgar 1991a). This can be obviated, however, if habitats are standardised, for example, by the use of identical, artificial substrata (Edgar 1991b, Gee \& Warwick 1996, Glasby 1998, Dahl \& Dahl 2002, Smith \& Rule 2002). Two broad categories of artificial substrata have been used in the study of marine communities: (1) planar surfaces (such as tiles and panels), and (2) complex substrata (such as nests of pan scourers), which mimic natural habitats (Gee \& Warwick 1996). While planar surfaces tend to become colonised by suspension-feeding, sessile assemblages, complex substrata are generally colonised by assemblages of motile, grazing and deposit-feeding species (Myers \& Southgate 1980, Edgar 1991b, Gee \& Warwick 1996, Kendall et al. 1996). The use of complex, artificial substrata has been repeatedly advocated for monitoring environmental impact, and this approach is rapidly gaining popularity in this field (De Pauw et al. 1986, Hoskin 1995, Hillebrand \& Sommer 1997, Edgar \& Klumpp 2003, Lemmens 2003, Mirto \& Danovaro 2004). Two problems with this method potentially exist: (1) resulting assemblages may be an artificially selected subset of adjacent, natural communities, and thus may not be representative of natural communities (Smith \& Rule 2002); and (2) the scales over which targeted assemblages recruit are often unknown (Morrisey et al. 1992, Glasby 1998). In a recent paper, Smith \& Rule (2002) demonstrated that assemblages of motile fauna recruiting to artificial substrata were generally not representative of adjacent, natural communities, and suggested that the utility of artificial substrata in pollution monitoring studies may thus be limited. However, other authors have reported conflicting results, suggesting that assemblages recruiting to complex artificial substrata do adequately represent natural communities (Myers \& Southgate 1980, Dean \& Connell 1987, Edgar 1991b).

Despite the array of studies investigating the scales of spatial variation in recruiting sessile assemblages (for examples, see: Keough 1983, Downes \& Keough 1998, Glasby 1998, Smith \& Witman 1999, Watson \& Barnes 2004), there remains a relative paucity of studies investigating spatial variation in the recruitment of motile assemblages from subtidal, hard-substrata. Where spatial variation has been quantified, motile assemblages have been shown to vary over scales of 100s of metres to kilometres (Edgar 1991a, Kendall et al. 1996, Dahl \& Dahl 2002, Flores et al. 2002, Norderhaug et al. 2002, Edgar \& Klumpp 2003). However, with the exception of Hereu et al. (2004), Edgar \&
Klumpp (2003) and Smith \& Rule (2002), small-scale variation in recruitment (over 10s of metres or less) has not been examined for motile fauna.

In the Solitary Islands Marine Park (SIMP), NSW, Australia, large-scale investigations of benthic recruitment are confounded by variation in benthic community structure across a number of gradients (e.g. crossshelf, depth) (Harriott et al. 1994, Smith \& Rule 2002). Nearshore, benthic communities are dominated by a macrophyte and sessile, suspension-feeding assemblage (Smith \& Simpson 1991). In contrast, corals dominate the offshore, island-associated communities (Harriott et al. 1994). Planar, artificial substrata have been utilised in a number of small-scale studies to quantify recruitment of sessile fauna at island sites (Holmes et al. 1997, Fairfull \& Harriott 1999, Harriott \& Banks 2002). In addition, Smith \& Rule (2002) used complex, artificial substrata to quantify recruitment of motile fauna, and to investigate how well these assemblages represented adjacent natural communities at a single nearshore site. However, to date, no information regarding large-scale (100s of metres to kilometres) variation in recruitment is available.

Given the current state of knowledge regarding motile fauna in the SIMP, and the emergence of artificial substrata as a monitoring tool, we used complex, artificial substrata to examine 2 main questions: (1) over what spatial scales does recruitment of motile invertebrate assemblages vary, and (2) how does the structure of recruiting motile, benthic assemblages vary between offshore, island-associated reefs within the SIMP.

\section{MATERIALS AND METHODS}

The structure of invertebrate assemblages recruiting to artificial substratum units (ASUs) was investigated over a range of spatial scales within the Solitary Islands Marine Park (SIMP) on the mid-north coast of NSW, Australia (Fig. 1). Two island sites, North West Solitary Island (hereafter NW Solitary) and North Solitary Island (hereafter North Solitary) were chosen for this study as they provide a conveniently broad scale (separated by approximately $14 \mathrm{~km}$ ) for studies on spatial variation in recruitment. Both islands are characterised by extensive sublittoral, rocky reef, which extends on the western (lee-ward) side to approximately $20 \mathrm{~m}$ depth. Scleractinian coral coverage at both sites is high for this region, with little or no macroalgal cover (Harriott et al. 1994). All sites were established on the western sides of the islands, where typically, benthic communities are more diverse, and habitats are more sheltered from the prevailing wave climate.

A fully nested design (after Morrisey et al. 1992) was used to investigate spatial variation in recruitment. 


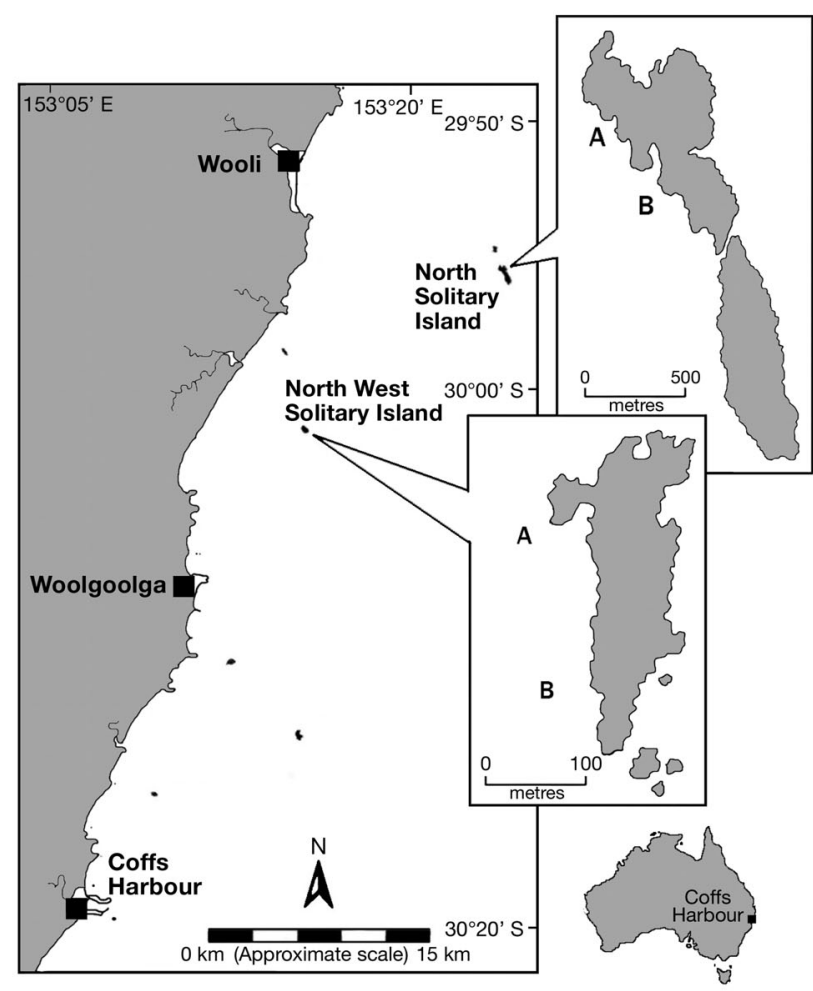

Fig. 1. Solitary Islands Marine Park (SIMP) showing the islands used in the study: North West Solitary Island and North Solitary Island. Expanded sections show the position of each location (A and B) used within each island

Four spatial scales (metres, 10s of metres, 100s of metres, kilometres) were examined with the 2 islands representing the largest scale. Within each island, 2 locations approximately $100 \mathrm{~m}$ apart were established. Within each of these locations, 3 sites approximately $20 \mathrm{~m}$ apart and measuring $5 \times 5 \mathrm{~m}$ were established in a triangular pattern (10s of metres). Three racks were anchored within each site approximately $2 \mathrm{~m}$ apart (metre scale). Each rack held 5 replicate samples, of which 4 were sorted for the present study. All sites were established between 6 and $8 \mathrm{~m}$ depth, as several authors (Edgar 1991b, Smith 1996) have found that small differences in depth have a significant influence on the structure of epifaunal invertebrate communities.

The artificial substratum units used in this study were nests of 3 nylon pan scourers tied with a plastic cable tie (Smith \& Rule 2002). Replicate samples were attached to an aluminium rack and fastened tightly with cable ties. Racks were manufactured in such a way that the replicate ASUs were held the same distance apart (approx. $30 \mathrm{~cm}$ ) and $20 \mathrm{~cm}$ above the substratum. Each rack was anchored to rocky substratum using rock-climbing pitons, which are well suited to this type of work as they are very strong, pliable and rust resistant.
All sample units were deployed on SCUBA, and were left in place for a period of 5 mo over the Austral summer (October-February). Several authors (Edgar 1991a, Smith \& Rule 2002) have suggested that any artificial substratum should be deployed over periods of highest recruitment, and Gee \& Warwick (1996) suggested that 5 mo was the optimum period of time for ASUs similar to the ones used in the current study.

Artificial substrata were collected by covering with a plastic bag and severing the cable tie that secured them to the rack with wire cutters. Samples were fixed in a solution of $10 \%$ seawater/formalin, and once processed, transferred to $70 \%$ ethanol. Samples were then pulled apart and the remaining matrix was sieved through a standardised $1 \mathrm{~mm}$ mesh. All small macrofauna (1 to $15 \mathrm{~mm}$ ) retained were then identified to the highest possible taxonomic resolution and counted. Colonial species (e.g. sponges and bryozoans) were not included in the analysis.

Differences in the structure of recruiting assemblages at all levels of the hierarchical design were evaluated using a range of both univariate and multivariate analyses. Species richness $(S)$, abundance $(\mathrm{N})$, and the abundances of a number of major taxonomic groups (amphipods, bivalves, polychaetes, decapods) were analysed using a 4-factor nested analysis of variance (ANOVA) with the Minitab statistical package (Minitab 1996). For all data, homogeneity of variances was checked before analysis using Levene's test. All factors (Island, Location, Site, Rack) were considered to be random.

All multivariate data were analysed using the PRIMER computer software package (PRIMER 2001). Species-abundance data were 4 th-root transformed to reduce the influence of large counts (Field et al. 1982) and subjected to non-metric multidimensional scaling (nMDS) ordination, which allows data to be visually explored. In most cases, Kruskal's stress values were high for 2-dimensional solutions $(>0.20)$, and so 3 dimensional solutions were generated (Clarke \& Warwick 1994). These were rotated to best show spatial patterns. Differences between all hierarchical levels were evaluated with a series of 1-way analysis of similarity (ANOSIM) tests. Pair-wise comparisons were performed on all tests that returned significant results to determine which groups of samples were responsible for the observed differences. Significance levels of pairwise comparisons at each level of the hierarchical design were adjusted for multiple comparisons using the Bonferroni technique (Smith \& Simpson 1991, Glasby 1998, Stark 2000, Sokal \& Rohlf 2001); the significance level ( $\alpha=0.05)$ was adjusted using the formula:

$$
\alpha^{\prime}=1-(1-\alpha)^{1 / k}
$$


where $\alpha^{\prime}$ is the adjusted significance level, and $k$ is the number of planned pairwise comparisons. The assemblages of species that were responsible for differences between samples were determined using SIMPER (similarity percentage) breakdowns.

\section{RESULTS}

During this investigation, several racks (g3, i3 and 13 from North Solitary) were lost due to inclement weather. A total of 49432 individuals, representing 433 invertebrate taxa and 1 species of fish, were recorded from the remaining 129 samples. Of these, 75 taxa were found only at North Solitary and 117 taxa were found solely at NW Solitary. Of all invertebrate species recorded, only $48(11 \%)$ were sessile forms. These included bivalves, terebellid and sabellid polychaetes, barnacles and ascidians; however, with the exception of 3 bivalve species (Hiatella australis, Musculus varicosus, Pinctada fucata), and the polychaetes, Pista sp. and Branchioma nigromaculata, sessile invertebrates had very low abundances. Species richness $(S)$ was consistently around 60 species per sample (Fig. 2). The number of individuals in each sample ranged from a minimum of 171 (Rack d1, NW Solitary) to a maximum of 604 individuals (Rack e1, NW Solitary). Samples from NW Solitary were numerically dominated by the bivalve $H$. australis ( $20.2 \%$ of total abundance), while the amphipod Mallacoota euroka dominated samples a) Species richness $(S)$

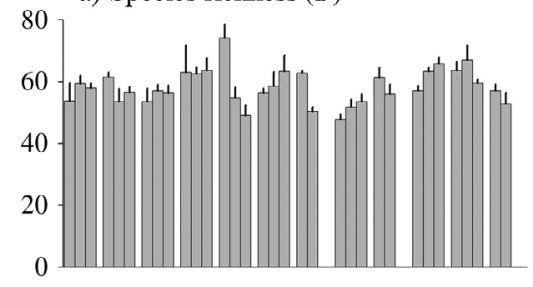

c) Amphipods
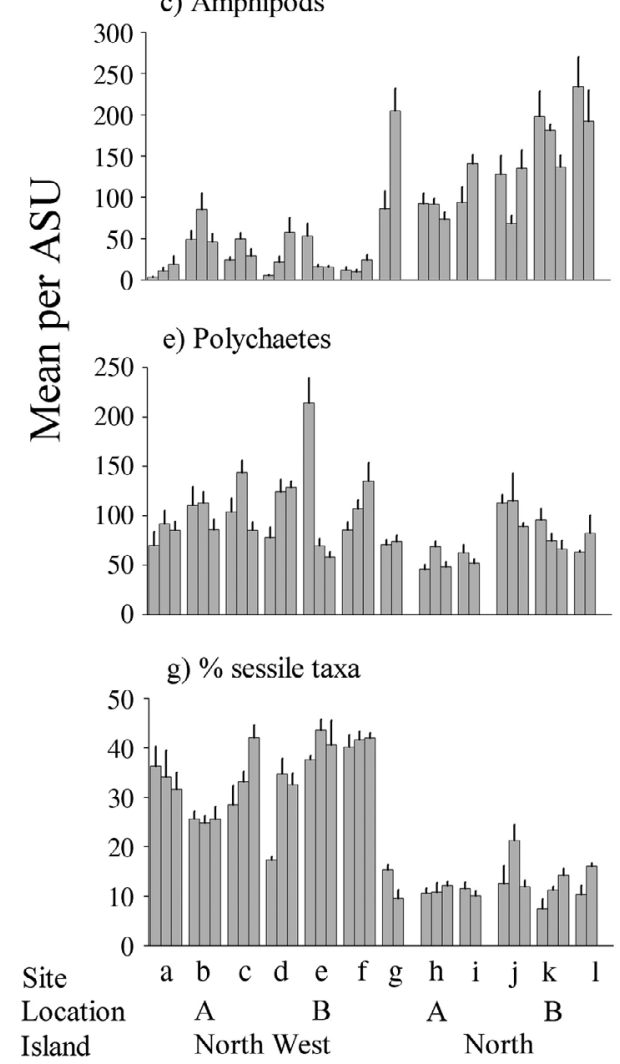

b) Abundance (N)

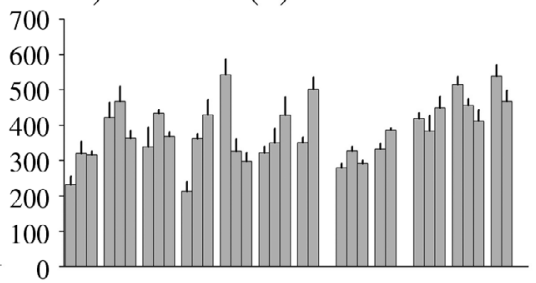

d) Bivalves

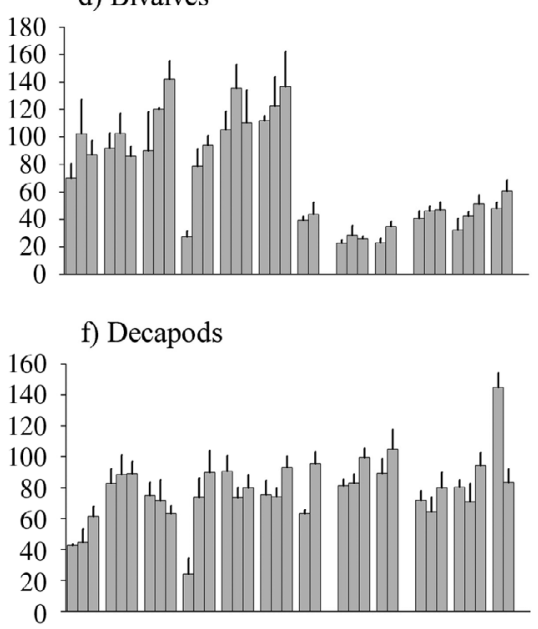

h) $\%$ motile taxa

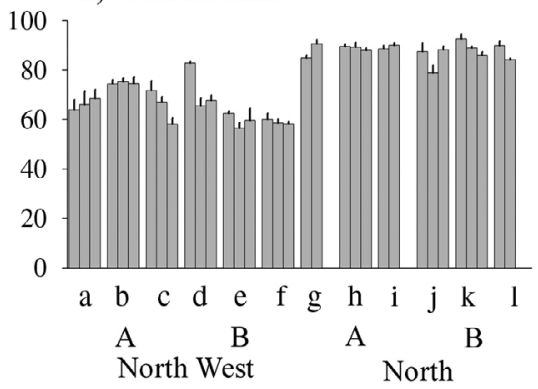

Fig. 2. Mean $(+\mathrm{SE})$ values for species richness $(S)$, abundance $(\mathrm{N})$, major taxonomic groups and percentage of total abundance contributed by sessile and motile fauna per ASU. There were 3 racks nested within each of 3 sites nested within each of 2 locations within each island. Racks g3, i3 (North Solitary A) and 13 (North Solitary B) were lost during the study period 
from North Solitary ( $22.5 \%$ of total abundance). Generally, sessile taxa contributed a much higher proportion to total abundance at NW Solitary than at North Solitary, and this was mainly due to the dominance of $H$. australis at this island (Fig. 2).

\section{Univariate analyses}

While significant differences were observed at the smallest spatial scale (metres between racks) for species richness and abundance, significant differences were not observed at the largest spatial scales for these variables (Table 1, Fig. 2). This was probably a result of the very high variation across the smallest scale. The mean abundance of sessile fauna was significantly higher at NW Solitary than at North Solitary; however, there was no difference in the abundance of motile fauna between the 2 islands. Both of these categories returned significant differences at the smallest spatial scale (Table 1, Fig. 2). For all of the taxonomic groups analysed, significant differences between mean abundances were evident at the smallest spatial scale. In addition, the abundance of amphipods and bivalves was significantly different between the 2 islands, with North Solitary supporting a higher mean abundance of amphipods, and NW Solitary supporting a higher mean abundance of bivalves (Fig. 2, Table 1). Both of these groups also displayed significant differences between sites (10s of metres). The abundance of decapods was found to vary significantly at the smallest spatial scale, and between the 2 islands. Polychaetes were the only group that returned significant differences between locations (100s of metres).

Variance estimates for each spatial scale were calculated (Underwood 1981) for species richness $(S)$, abundance $(\mathrm{N})$, and for each major taxonomic group analysed (Table 1). Variance estimates provide an indication of the contribution to the total variance of each spatial scale. For species richness, the majority of variation was at the within-rack level. This was not the case for abundance $(\mathrm{N})$, which had the highest variability between racks. The majority of variance for sessile fauna was at the between-island scale; however, for motile fauna the highest variance was found between racks. The variance for amphipods, bivalves and decapods was highest at the largest spatial scale. For total polychaetes, the variance was highest between racks. For all taxonomic groups, the residual (within-rack) variance was the second highest contributor to the total variance.

Table 1. Summary of the 4-factor nested ANOVA for species richness, abundance $(\mathrm{N})$, major taxonomic groups and proportion of sessile and motile fauna. Variance components $(v c)$ derived from the analysis are reported as percentages of the total. Negative estimates are assumed to be zero (Underwood 1981). The level which contributed the highest proportion to total variance in each category is shown in bold. ${ }^{* * *} \mathrm{p} \leq 0.001$; ${ }^{* *} \mathrm{p} \leq 0.01$; ${ }^{*} \mathrm{p} \leq 0.05$; ns: $\mathrm{p} \geq 0.05$

\begin{tabular}{|c|c|c|c|c|c|}
\hline Source of variation & $\mathrm{df}$ & MS & $F$ & $\mathrm{p}$ & VC \\
\hline \multicolumn{6}{|l|}{ Species richness $(S)$} \\
\hline Island & 1 & 17.26 & 0.04 & ns & 0.00 \\
\hline Location (I) & 2 & 396.37 & 3.85 & ns & 12.50 \\
\hline Site $[\mathrm{L}(\mathrm{I})]$ & 8 & 103.01 & 0.89 & ns & 0.00 \\
\hline $\operatorname{Rack}\{\mathrm{S}[\mathrm{L}(\mathrm{I})]\}$ & 21 & 115.89 & 2.52 & $* * *$ & 24.63 \\
\hline Error & 96 & 45.92 & & & 62.86 \\
\hline \multicolumn{6}{|l|}{ Abundance (N) } \\
\hline Island & 1 & 63929.47 & 0.82 & ns & 0.00 \\
\hline Location (I) & 2 & 78485.83 & 2.87 & ns & 15.72 \\
\hline Site $[\mathrm{L}(\mathrm{I})]$ & 8 & 27348.46 & 1.34 & ns & 6.94 \\
\hline $\operatorname{Rack}\{\mathrm{S}[\mathrm{L}(\mathrm{I})]\}$ & 21 & 19675.62 & 5.34 & $* * *$ & 40.77 \\
\hline Error & 96 & 3687.39 & & & 36.577 \\
\hline \multicolumn{6}{|l|}{ Amphipods } \\
\hline Island & 1 & 373775.65 & 22.26 & * & 68.45 \\
\hline Location (I) & 2 & 17579.33 & 1.62 & ns & 2.51 \\
\hline Site $[\mathrm{L}(\mathrm{I})]$ & 8 & 10858.72 & 3.25 & $*$ & 8.67 \\
\hline $\operatorname{Rack}\{\mathrm{S}[\mathrm{L}(\mathrm{I})]\}$ & 21 & 3342.14 & 3.13 & $* * *$ & 7.22 \\
\hline Error & 96 & 1066.94 & & & 13.16 \\
\hline \multicolumn{6}{|l|}{ Bivalves } \\
\hline Island & 1 & 121607.06 & 68.74 & * & 65.40 \\
\hline Location (I) & 2 & 1769.21 & 0.47 & ns & 0.00 \\
\hline Site $[\mathrm{L}(\mathrm{I})]$ & 8 & 3775.07 & 3.54 & $* *$ & 8.89 \\
\hline $\operatorname{Rack}\{\mathrm{S}[\mathrm{L}(\mathrm{I})]\}$ & 21 & 1066.70 & 1.72 & $*$ & 4.03 \\
\hline Error & 96 & 618.94 & & & 21.68 \\
\hline \multicolumn{6}{|l|}{ Polychaetes } \\
\hline Island & 1 & 26592.455 & 3.41 & $\mathrm{~ns}$ & 15.03 \\
\hline Location (I) & 2 & 7796.40 & 5.42 & $*$ & 10.25 \\
\hline Site $[\mathrm{L}(\mathrm{I})]$ & 8 & 1439.86 & 0.36 & $\mathrm{~ns}$ & 0.00 \\
\hline $\operatorname{Rack}\{\mathrm{S}[\mathrm{L}(\mathrm{I})]\}$ & 21 & 4028.08 & 7.14 & $* * *$ & 45.73 \\
\hline Error & 96 & 564.55 & & & 28.99 \\
\hline \multicolumn{6}{|l|}{ Decapods } \\
\hline Island & 1 & 25227.39 & 27.55 & $*$ & 40.87 \\
\hline Location (I) & 2 & 915.83 & 0.50 & $\mathrm{~ns}$ & 0.00 \\
\hline Site $[\mathrm{L}(\mathrm{I})]$ & 8 & 1816.61 & 1.64 & $\mathrm{~ns}$ & 7.06 \\
\hline $\operatorname{Rack}\{\mathrm{S}[\mathrm{L}(\mathrm{I})]\}$ & 21 & 1107.98 & 4.17 & $* * *$ & 23.35 \\
\hline Error & 96 & 266.17 & & & 28.72 \\
\hline \multicolumn{6}{|l|}{ Sessile fauna } \\
\hline Island & 1 & 178124.30 & 22.42 & * & 63.78 \\
\hline Location (I) & 2 & 15866.70 & 1.95 & ns & 2.89 \\
\hline Site $[\mathrm{L}(\mathrm{I})]$ & 8 & 32333.40 & 1.45 & ns & 2.85 \\
\hline $\operatorname{Rack}\{\mathrm{S}[\mathrm{L}(\mathrm{I})]\}$ & 21 & 57832.3 & 3.66 & $* * *$ & 12.38 \\
\hline Error & 96 & 356445.3 & & & 18.11 \\
\hline \multicolumn{6}{|l|}{ Motile fauna } \\
\hline Island & 1 & 63929 & 0.81 & ns & 0.00 \\
\hline Location (I) & 2 & 156972 & 5.85 & ns & 15.72 \\
\hline Site $[\mathrm{L}(\mathrm{I})]$ & 8 & 218788 & 1.37 & ns & 6.94 \\
\hline $\operatorname{Rack}\{\mathrm{S}[\mathrm{L}(\mathrm{I})]\}$ & 21 & 413188 & 5.34 & $* * *$ & 40.77 \\
\hline Error & 96 & 353989 & & & 36.57 \\
\hline
\end{tabular}




\section{Multivariate analyses}

Differences between islands

The nMDS plot for samples pooled by location indicates that considerable variation in community structure existed between the 2 islands, and between each of the 2 locations within islands (Fig. 3). NW Solitary and North Solitary form 2 very distinct groups within the plot, with samples from NW Solitary grouping to the left and samples from North Solitary grouping to the right. Within each island, the 2 locations also form distinct groupings, with NW Solitary A forming a relatively tight cluster towards the middle of the plot, and NW Solitary B forming a looser group spread throughout the left hand-side of the plot (see also Fig. 4a). The same pattern applies to North Solitary, where North A forms a tight cluster below North B (see also Fig. 4b). There is a small overlap between the 2 locations at North Solitary. The 4 samples from NW Solitary B at the extreme left of the plot (see also Fig. 4a) are considerably different from the others within their location. These 4 samples were all taken from the same rack (Rack d1, NW Solitary), which was in close proximity to a large sandy patch. It is possible that these ASUs were sampling a different benthic community (see below). The nMDs plots for samples pooled by site within each location (Fig. 4) show considerable overlap between

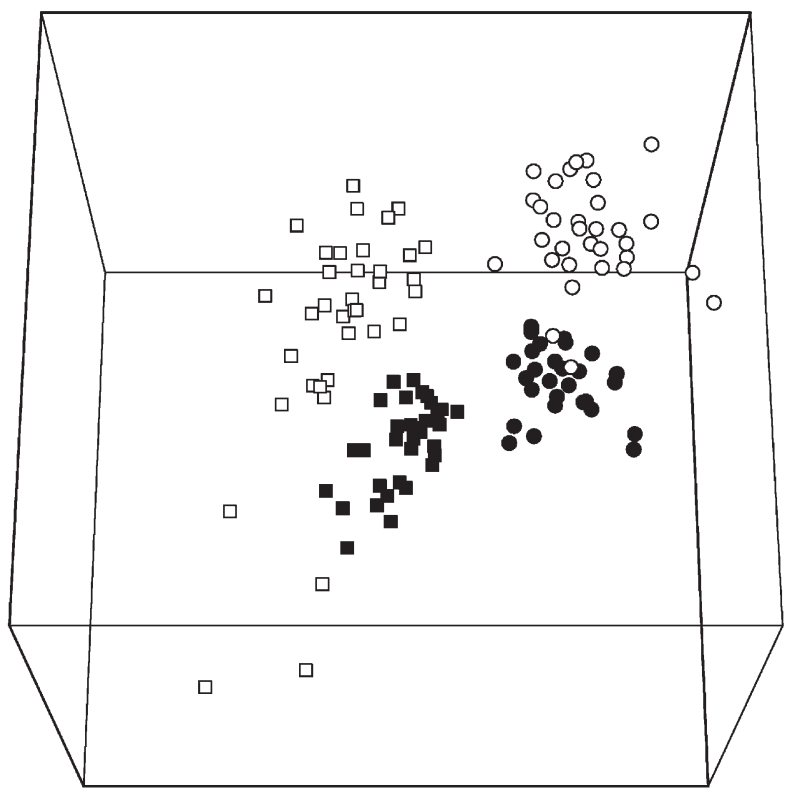

Fig. 3. Three-dimensional, non-metric multidimensional scaling (nMDS) ordination of samples from each location. The ordination has been rotated to best display separation of sample groups; squares: NW Solitary; circles: North Solitary; filled symbols: Location $A_{\text {; }}$ unfilled symbols: Location B. Kruskal's stress $=0.17$ most sample groups. At NW Solitary A (Fig. 4a), Sites b and $\mathrm{c}$ form a homogeneous cluster to the right of the distinct Site a group. At NW Solitary B (Fig. 4b), samples from Site d lie to the left of those from Sites e and f. Again, the 4 samples to the extreme left of this plot are all from the same rack (Rack d1). At North Solitary A (Fig. 4c), samples form 3 loose groups, with those from Site $g$ generally lying below those from Sites $h$ and i. Samples from Site j at North Solitary B (Fig. 4d) lie below those from Sites k and l. Samples from Site 1 form a loose cluster to the left of the plot.

The 1-way ANOSIM (Table 2) revealed a significant difference for the comparison between islands $(\mathrm{R}=$ 0.687, $\mathrm{p}=0.001$ ). The SIMPER breakdowns show that, overall, the recruiting assemblages between the 2 islands were only $46 \%$ similar. While large differences existed between islands for mean abundances of some species (e.g. Hiatella australis), the contributions of each species to the overall difference was relatively small (Table 3). The species contributing the most, the porcellanid crab Ancylocheles gravelei, only accounted for $1.55 \%$ of the difference between the 2 islands, with means of 13.3 and 0.7 individuals per sample at NW Solitary and North Solitary, respectively. The 20 highest-ranked species combined accounted for a total of $22 \%$ of the dissimilarity between islands. Although samples from NW Solitary were dominated by the bivalve $H$. australis, and samples from North Solitary were dominated by the amphipod Mallacoota euroka, these 2 species only contributed a total of $2.8 \%$ of the difference between the 2 islands. All polychaetes had higher mean abundances at NW Solitary except for Chrysopetalid sp. 2. A similar pattern was evident for bivalves which, except for Bivalve sp. 13, were more abundant at NW Solitary. All high-ranking amphipod species had higher mean abundances at North Solitary than NW Solitary (Table 3).

In terms of total abundance, the highest-ranked polychaetes and bivalves (Table 3) accounted for $32.23 \%$ of the total number of individuals at NW Solitary. These same species accounted for a total of $5.15 \%$ of individuals at North Solitary. The highest-ranked amphipods at North Solitary accounted for $31.57 \%$ of the total abundance, while the same amphipod species at NW Solitary accounted for only $7.14 \%$ of the total abundance. These results suggest a shift in dominance patterns between islands, from bivalves at NW Solitary, to amphipods at North Solitary.

\section{Differences within islands}

North West Solitary Island. There was a significant difference in the recruiting assemblage structure between locations at NW Solitary $(R=0.345, p=0.001)$. 
a) NW Solitary A (0.18)

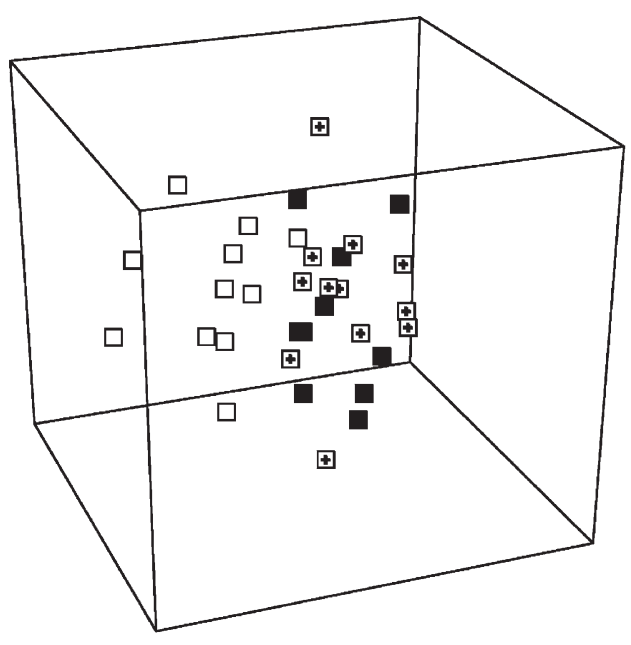

c) North Solitary A (0.18)

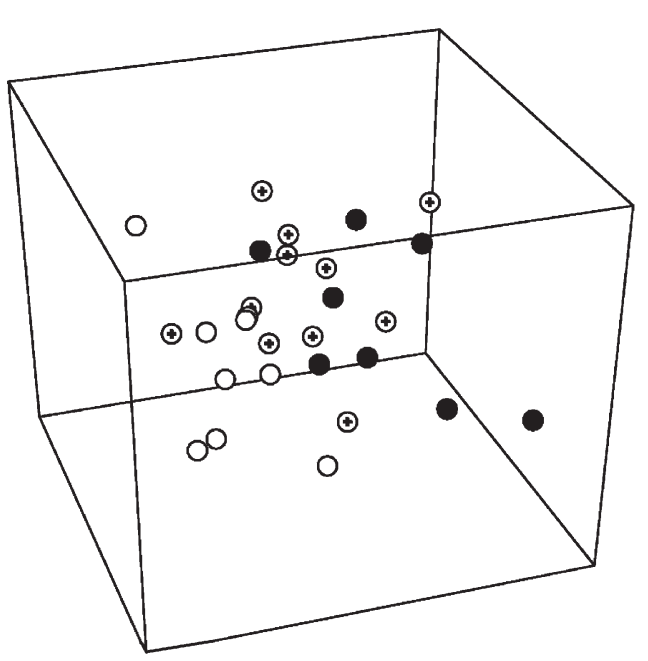

b) NW Solitary B (0.16)

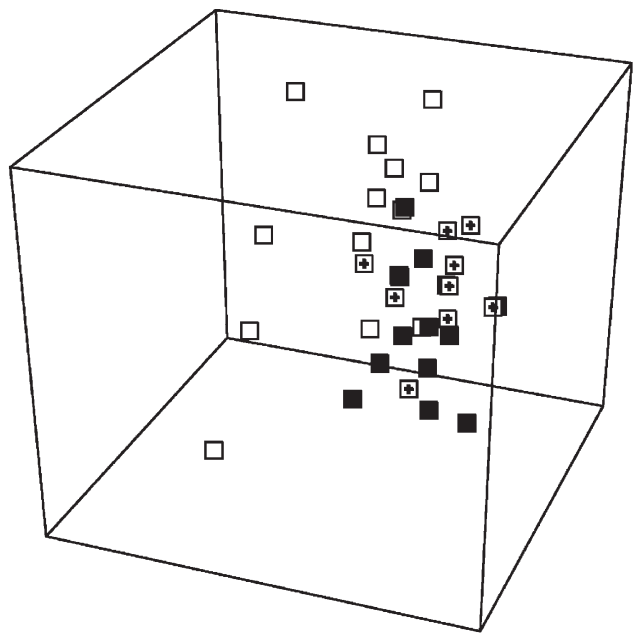

d) North Solitary B (0.19)

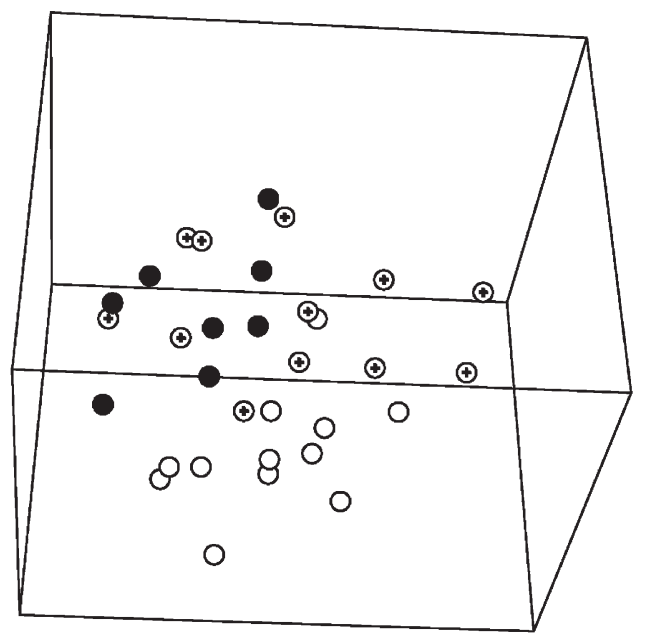

Fig. 4. Three-dimensional, non-metric multidimensional scaling (nMDS) ordination of samples from each site at each location; (a) NW Solitary A, (b) NW Solitary B, (c) North Solitary A and (d) North Solitary B. Each ordination has been rotated to best display separation of sample groups. Unfilled symbols: Site 1 (Sites a, d, g and j); crossed symbols: Site 2 (Sites b, e, h and k); filled symbols: Site 3 (Sites c, f, i and l). Kruskal's stress values given in parentheses

The global test for differences between sites within each location at NW Solitary also returned significant differences at both locations (Table 2). The ANOSIM performed on data from NW Solitary A revealed a significant difference between sites $(\mathrm{R}=0.251, \mathrm{p}=0.001)$, and the pair-wise comparison showed that all sites were significantly different from each other within this location (Table 2). The global test for differences between racks within sites revealed no significant differences at this location (Table 2). The ANOSIM between site groups at NW Solitary B returned a significant result $(R=0.163, p=0.001)$. The pairwise breakdowns show that Site d was significantly differ- ent to both Sites e and $\mathrm{f}$ (Table 2), while the latter sites were not significantly different from each other. The global test for differences between racks within sites at this location revealed a significant difference for racks within Site e. Pair-wise comparisons of racks within this site, however, revealed no significant differences between any of the racks. This result must be viewed with caution, as the R-values for tests between e1, and both e2 and e3 are high enough $(R=0.865$ and 0.896 , respectively) to suggest little overlap between the respective communities (Clarke \& Gorley 2001). This non-significant result may be an artefact of the Bonferroni correction used here. 
Table 2. Results of the 1-way ANOSIM testing differences in community structure between Islands, Locations, Sites and Racks. See the text for details of pairwise comparisons of Racks. Significance levels adjusted by the Bonferroni procedure are shown in brackets. Significant values are shown in bold

\begin{tabular}{|c|c|c|c|c|}
\hline $\begin{array}{l}\text { Source } \\
\text { of variation }\end{array}$ & Global test & $\begin{array}{l}\text { Pairwise } \\
\text { comparison }\end{array}$ & $\mathrm{R}$ & $\mathrm{p}$ \\
\hline Islands & & & 0.687 & 0.001 \\
\hline \multicolumn{5}{|l|}{ Locations (0.025) } \\
\hline & & NWA $\times$ NWB & 0.345 & 0.001 \\
\hline & & $\mathrm{NA} \times \mathrm{NB}$ & 0.368 & 0.001 \\
\hline \multicolumn{5}{|l|}{ Sites (0.043) } \\
\hline & NWA & & 0.251 & 0.001 \\
\hline & & Site $a \times$ Site $b$ & 0.356 & 0.001 \\
\hline & & Site $\mathrm{a} \times$ Site $c$ & 0.258 & 0.001 \\
\hline & & Site $\mathrm{b} \times$ Site $c$ & 0.167 & 0.003 \\
\hline & NWB & & 0.163 & 0.001 \\
\hline & & Site $d \times$ Site e & 0.197 & 0.001 \\
\hline & & Site $d \times$ Site $\mathrm{f}$ & 0.232 & 0.001 \\
\hline & & Site $\mathrm{e} \times$ Site $\mathrm{f}$ & 0.049 & 0.193 \\
\hline & NA & & 0.289 & 0.001 \\
\hline & & Site $g \times$ Site $h$ & 0.324 & 0.001 \\
\hline & & Site $g \times$ Site $\mathrm{i}$ & 0.209 & 0.015 \\
\hline & & Site $\mathrm{h} \times$ Site $\mathrm{i}$ & 0.295 & 0.001 \\
\hline & NB & & 0.295 & 0.001 \\
\hline & & Site $\mathrm{j} \times$ Site $\mathrm{k}$ & 0.240 & 0.001 \\
\hline & & Site $\mathrm{j} \times$ Site 1 & 0.500 & 0.001 \\
\hline & & Site $\mathrm{k} \times$ Site $\mathrm{l}$ & 0.197 & 0.017 \\
\hline \multicolumn{5}{|l|}{ Racks (0.002) } \\
\hline & NWA a & & 0.307 & 0.018 \\
\hline & NWA b & & 0.090 & 0.194 \\
\hline & NWA C & & 0.096 & 0.281 \\
\hline & NWB d & & 0.301 & 0.003 \\
\hline & NWB e & & 0.616 & 0.001 \\
\hline & NWB f & & 0.356 & 0.010 \\
\hline & NA g & & 0.792 & 0.290 \\
\hline & NA $h$ & & 0.208 & 0.520 \\
\hline & NA i & & 0.198 & 0.200 \\
\hline & $\mathrm{NB} j$ & & 0.431 & 0.002 \\
\hline & NB $k$ & & 0.322 & 0.001 \\
\hline & NB 1 & & -0.052 & 0.629 \\
\hline
\end{tabular}

North Solitary Island. There was a significant difference in the recruiting assemblage structure between locations at North Solitary $(\mathrm{R}=0.368, \mathrm{p}=$ 0.001). The global tests for differences between sites within locations at North Solitary returned significant differences for all locations (Table 2). The ANOSIM between site groups at North Solitary A revealed a significant difference $(\mathrm{R}=0.289, \mathrm{p}=0.001)$ between sites. Pair-wise comparisons between site groups revealed that Site $\mathrm{h}$ was significantly different from both Sites $g$ and i (Table 2). Global tests between racks within sites at this location returned a nonsignificant result for each test (Table 2). It must be noted that a rack from both Sites $g$ and i was lost during this study and this may have influenced this result. The ANOSIM between site groups at North Solitary B revealed a significant $(R=0.289, p=0.001)$ difference between sites (Table 2). Pairwise comparisons of site groups reveal that Site $j$ was significantly different from both Sites $\mathrm{k}$ and 1 (Table 2) at this location. A single rack was lost from Site l during this study, and this may have affected the result. Global tests for differences between racks within sites at this location revealed a significant difference between racks within Site $\mathrm{k}$ (Table 2). Pairwise comparisons, however, revealed no significant differences between any of the racks within this site.

\section{DISCUSSION}

The results of this study suggest that the recruitment of motile invertebrate assemblages to artificial substrata within the SIMP is highly variable over a range of spatial scales. Distinct motile assemblages recruited to artificial substrata both between islands (kilometres) and between locations (100s of metres). Significant differences in assemblage structure were generally found over smaller spatial scales (10s of metres). However, differences in assemblage structure were generally not apparent at the smallest scale (metres between racks). While several studies investigating spatial variation in recruitment of motile assemblages have found significant variation over large spatial scales $(100 \mathrm{~s}$ of metres to kilometres) (Edgar 1991b, Kendall et al. 1996, Glasby 1998, Dahl \& Dahl 2002, Flores et al. 2002, Norderhaug et al. 2002), very few studies examining variation over small spatial scales in the recruitment of motile fauna from subtidal, hard-substrata are available for comparison. Smith \& Rule (2002) utilised identical, artificial substrata as those used here, and found no significant differences in the structure of motile assemblages recruiting to artificial substrata placed approximately 15 m apart. Edgar \& Klumpp (2003) found that motile assemblages recruiting to 2 different artificial plant units varied between islands separated by kilometres, but not at the within-island scale (10s to 100s of metres). Flores et al. (2002) examined recruitment of brachyuran megalopae over a range of spatial scales, and found that while significant differences existed between areas separated by $1.5 \mathrm{~km}$, no variation was apparent at smaller scales (metres to 100 s of metres).

Despite the numerical dominance of the bivalve Hiatella australis at NW Solitary, very few sessile species recruited to artificial substrata during the current 
Table 3. SIMPER breakdowns for island groups. Only the 20 highest contributing species are shown. Bold values indicate the island with the largest mean abundance

\begin{tabular}{|c|c|c|c|c|}
\hline Species & $\begin{array}{l}\text { Taxonomic } \\
\text { information }\end{array}$ & $\begin{array}{c}\text { NW } \\
\text { Solitary } \\
\text { mean } \\
\text { abundance }\end{array}$ & $\begin{array}{c}\text { North } \\
\text { Solitary } \\
\text { mean } \\
\text { abundance }\end{array}$ & $\begin{array}{c}\text { Contri- } \\
\text { bution } \\
(\%)\end{array}$ \\
\hline Ancylocheles gravelei & Decapod & 13.3 & 0.7 & 1.55 \\
\hline Ampithoe kava & Amphipod & 2.4 & 26.6 & 1.53 \\
\hline Malacoota euroka. & Amphipod & 22.4 & 96.7 & 1.49 \\
\hline Pista sp. & Polychaete & 15.0 & 1.4 & 1.41 \\
\hline Hiatella australis & Bivalve & 73.0 & 11.7 & 1.31 \\
\hline Musculus varicosus & Bivalve & 8.6 & 1.1 & 1.21 \\
\hline Nematode sp. & Nematode & 3.7 & 0.4 & 1.19 \\
\hline Aora hebes & Amphipod & 1.1 & 5.2 & 1.06 \\
\hline Naxia sp. & Decapod & 2.1 & 0.4 & 1.01 \\
\hline Apseudid sp. 1 & Isopod & 4.7 & 11.1 & 0.99 \\
\hline Branchioma & & & & \\
\hline nigromaculata & Polychaete & 1.8 & 0.1 & 0.99 \\
\hline Pyrene sp. & Prosobranch & 0.7 & 3.3 & 0.97 \\
\hline Tanystylum hooperi & Pycnogonid & 2.2 & 10.5 & 0.96 \\
\hline Anemone sp. 4 & Anemone & 0.8 & 3.0 & 0.94 \\
\hline Thedomita sp. & Decapod & 0.6 & 2.5 & 0.93 \\
\hline Platynereis dumerilii & & & & \\
\hline antipoda & Polychaete & 17.9 & 3.8 & 0.92 \\
\hline Bivalve sp. 13 & Bivalve & 0.3 & 1.6 & 0.90 \\
\hline Chrysopetalid sp. & Polychaete & 0.1 & 1.3 & 0.90 \\
\hline Amphipholis squamata & Ophiuroid & 2.2 & 0.9 & 0.90 \\
\hline Ophiactus macrolepidota & Ophiuroid & 2.4 & 1.4 & 0.88 \\
\hline & & \multicolumn{2}{|c|}{ Cumulative \% } & 22.04 \\
\hline
\end{tabular}

study. Artificial substrata were generally colonised by a suite of mobile taxa such as peracarid crustaceans, polychaetes, echinoderms and gastropods. The trend for complex, artificial substrata to be colonised by motile assemblages has been previously reported (Myers \& Southgate 1980, Edgar 1991b, Kendall et al. 1996, Smith \& Rule 2002). Edgar (1991b) found that rope fibre habitats were colonised by a suite of motile fauna. Kendall et al. (1996) reported that nests of panscourers were colonised by an amphipod- and polychaete-dominated assemblage, and that molluscs and echinoderms were also well represented. Norderhaug et al. (2002) found that kelp mimics were colonised mainly by amphipods and gastropods.

Artificial substrata are colonised by 2 main methods: (1) larval recruitment from the plankton, and (2) migration of adults and juveniles from adjacent habitats (Chapman 2002, Smith \& Rule 2002). In addition, individuals may arrive as a consequence of passive dispersal due to dislodgement during periods of increased turbulence (Smith \& Rule 2002), or through nocturnal emergence into the water column (Edgar 1991b). Several authors (Gee \& Warwick 1996, Kendall et al. 1996) suggest that complex, artificial substrata are generally colonised by motile species with directly developing larvae, and that these types of artificial substrata tend to under-sample species with pelagic development. However, the reproductive ecology of many Australian epifaunal species is poorly known (Keough \& Butler 2000). During the current study, a range of larval, juvenile and adult individuals were recorded from artificial substrata. Individuals of some species with pelagic larvae, such as the bivalves Hiatella australis and Musculus varicosus, had a uniform size, and thus had probably recruited over a short period of time. Conversely, individuals of other species, such as the bivalve Pinctada fucata, covered a wide range of body sizes; thus, individuals of varying sizes probably recruited at different times throughout the deployment period. For motile taxa, juvenile, sub-adult and gravid, adult specimens of amphipods, decapods and isopods were recorded. Additionally, epitokous nereid and syllid polychaetes were found in many samples; thus, while some species recorded during the present study clearly use a planktonic development strategy (e.g. barnacles and bivalves), the mobility of the majority of species suggests that migration of adults and juveniles from localised habitats is an important mode of colonisation for these types of artificial substrata.

Across the largest spatial scale, physical differences between the 2 islands may be partially responsible for the observed differences in assemblage structure. While both islands have similar benthic community structure (Harriott et al. 1994), NW Solitary is generally more turbid (M. J. Rule pers. obs.), and the water temperature is on average between 0.5 and $1.0^{\circ} \mathrm{C}$ lower than North Solitary (Solitary Islands Marine Parks Authority unpubl. data). Sessile fauna generally contributed to a much higher proportion of total abundance at NW Solitary than at North Solitary, mainly because of the numerical dominance of Hiatella australis. The increased proportion of sessile fauna at NW Solitary may be related to the increased turbidity at this island, as a higher suspended load may provide a greater food source for these types of organism. It must be noted, however, that this was not quantified during the study.

Over small spatial scales, the structure of adjacent habitats appears to have an important influence on the structure of assemblages recruiting to artificial substrata. Rack d1 from NW Solitary provides some evidence for this. This rack was anchored adjacent to a 
large sandy patch, and the resulting assemblage was very different to those found on other samples at this island (Fig. 4b). The dominance of bivalves and the proportion of sessile taxa were greatly reduced on this rack, and the abundance of decapods was also considerably lower on this rack than from any other during the study. The contribution of motile species was greater on this rack as a result of an increased number of polychaete species, which presumably migrated or recruited from the adjacent soft-sediment patch. Several authors have highlighted the importance of the structure and composition of surrounding, natural habitats to the structure of assemblages colonising artificial substrata (Myers \& Southgate 1980, Edgar 1991b, Chapman 2002, Norderhaug et al. 2002). Chapman (2002), who investigated colonisation of boulders by motile assemblages, suggested that the existing biota surrounding a new 'patch' of habitat can have a strong influence on the suite of colonising species. Norderhaug et al. (2002) found that the most abundant taxa recorded on kelp mimics were also the most abundant in adjacent, natural kelp holdfasts.

Artificial substrata have been repeatedly advocated for use in environmental impact studies as they are inexpensive, provide an identical, replicable habitat, and generally provide a high level of precision compared to natural habitats, a characteristic that may enhance the detection of environmental change (Edgar 1991b, Smith \& Rule 2002). The results of this study have important implications for environmental impact studies utilising artificial substrata in natural habitats. Typically, impact studies involve samples being taken immediately next to a source of impact, and at several control locations, 100s of metres or kilometres from the impact site (Morrisey et al. 1992, Bishop et al. 2002). Variation at the within-location scale is generally not examined, and comparisons between control and impacted locations may, therefore, be confounded by patchiness in assemblage structure over smaller scales than those being examined (Andrew \& Mapstone 1987, Morrisey et al. 1992, Glasby 1998). The spatial variation reported here must be taken into account when designing any environmental impact study. For any study employing complex, artificial substrata, replicate samples within control and impact locations separated by 100 s of metres or kilometres need to be separated by 10 s of metres to account for the high level of small-scale patchiness in recruiting assemblages.

Another issue that is likely to be important to the utility of artificial substrata in monitoring programs is the variation in assemblage structure over time. As many of the species recorded during the current study are motile, the assemblages recruiting to artificial substrata may be highly transient (Costello \& Myers 1996).
If this is the case, the use of these types of artificial substrata in monitoring programs may be limited (Smith \& Rule 2002). Several authors have, however, found repeatable spatial patterns in the recruitment of benthic assemblages (Farnsworth \& Ellison 1996, Osman \& Whitlatch 1998, Martinez \& Navarrete 2002). The current study represents part of an ongoing investigation into the recruitment of benthic assemblages to artificial substrata within the SIMP, and the persistence of spatial patterns through time is currently being examined.

The island sites investigated in this study are isolated from each other by large expanses of soft sediment. For those benthic species with pelagic larvae, propagules may be transported to the islands from outside the region (by the East Australian Current, EAC), however, arrival at either island is likely to be sporadic (Harriott et al. 1994, Smith \& Rule 2002). Larval exchange between North Solitary and NW Solitary may be possible; however, the reciprocal would be rare, as currents in the study area tend to flow southwards, and thus, North Solitary lies 'upstream' of NW Solitary. For species with non-pelagic larvae, the modes of exchange between islands are limited. Thus, in addition to the input of pelagic larvae of some species from outside the local area, locally produced larvae and migration of adults from local habitats may sustain and replenish motile assemblages at island sites within the study area.

Acknowledgements. We would like to thank K. Cornish, M. Vervenne, M. Dunn, A. Davey and S. Richards for boating and diving assistance. In addition, $\mathrm{K}$. Cornish helped design the racks and dealt with a number of logistical problems. C. Connell helped identify suitable sites, and assisted with boating issues. This work benefited greatly from conversations with Dr. S. Cairns (UNE) and Dr. J. Stark (Australian Antarctic Division), and 4 anonymous referees made useful comments on an earlier version of the manuscript. This project was funded through a UNE postgraduate research grant to M.J.R., and was assisted by the Co-op Bookshop Postgraduate Award.

\section{LITERATURE CITED}

Andrew NL, Mapstone BD (1987) Sampling and the description of spatial pattern in marine ecology. Oceanogr Mar Biol Annu Rev 25:39-90

Bertness MD, Gaines SD, Wahle RA (1996) Wind-driven settlement patterns in the acorn barnacle Semibalanus balanoides. Mar Ecol Prog Ser 137:103-116

Bishop MJ, Underwood AJ, Archambault P (2002) Sewage and environmental impacts on rocky shores: necessity of identifying relevant spatial scales. Mar Ecol Prog Ser 236: 121-128

Bourget E, DeGuise J, Daigle G (1994) Scales of substratum heterogeneity, structural complexity, and the early establishment of a marine epibenthic community. J Exp Mar Biol Ecol 181:31-51

Chapman MG (2002) Early colonization of shallow subtidal boulders in two habitats. J Exp Mar Biol Ecol 275:95-116 
Clarke KR, Gorley RN (2001) PRIMER v5: user manual/ tutorial. PRIMER-E, Plymouth

Clarke KR, Warwick RM (1994) Change in marine communities: an approach to statistical analysis and interpretation. Bourne Press, Plymouth

Costello MJ, Myers AA (1996) Turnover of transient species as a contributor to the richness of a stable amphipod (Crustacea) fauna in a sea inlet. J Exp Mar Biol Ecol 202: $49-62$

Dahl L, Dahl K (2002) Temporal, spatial and substrate-dependent variations of Danish hard-bottom macrofauna. Helgol Mar Res 56:1-21

Dean RL, Connell JH (1987) Marine invertebrates in an algal succession. II. Tests of hypotheses to explain changes in diversity with succession. J Exp Mar Biol Ecol 109: 217-247

De Pauw N, Roels D, Fontoura P (1986) Use of artificial substrates for standardized sampling of macroinvertebrates in the assessment of water quality by the Belgian Biotic Index. Hydrobiologia 133:237-258

Downes BJ, Keough MJ (1998) Scaling of colonisation processes in streams: parallels and lessons from marine hard substrata. Aust J Ecol 23:8-26

Eckman JE (1990) A model of passive settlement by planktonic larvae onto bottoms of differing roughness. Limnol Oceanogr 35:887-901

Edgar GJ (1991a) Artificial algae as habitats for mobile epifauna: factors affecting colonization in a Japanese sargassum bed. Hydrobiologia 226:111-118

Edgar GJ (1991b) Distribution patterns of mobile epifauna associated with rope fibre habitats within the Bathurst Harbour estuary, south-west Tasmania. Estuar Coast Shelf Sci 33:589-604

Edgar GJ, Klumpp DW (2003) Consistencies over regional scales in assemblages of mobile epifauna associated with natural and artificial plants of different shape. Aquat Bot 75:275-291

Fairfull SJL, Harriott VJ (1999) Succession, space and coral recruitment in a subtropical fouling community. Mar Freshw Res 50:235-242

Farnsworth EJ, Ellison AM (1996) Scale-dependent spatial and temporal variability in biogeography of mangrove root epibiont communities. Ecol Monogr 66:45-66

Field JG, Clarke KR, Warwick RM (1982) A practical strategy for analysing multispecies distribution patterns. Mar Ecol Prog Ser 8:37-52

Flores AAV, Cruz J, Paula J (2002) Temporal and spatial patterns of settlement of brachyuran crab megalopae at a rocky coast in Central Portugal. Mar Ecol Prog Ser 229: 207-220

Gee JM, Warwick RM (1996) A study of global biodiversity patterns in the marine motile fauna of hard substrates. J Mar Biol Assoc UK 76:177-184

Glasby TM (1998) Estimating spatial variability in developing assemblages of biota on subtidal hard substrata. Mar Freshw Res 49:429-437

Gunnill FC (1982) Effects of plant size and distribution on the numbers of invertebrate species and individuals inhabiting the brown alga Pelvetia fastigata. Mar Biol 69:263-280

Harriott VJ, Banks SA (2002) Latitudinal variation in coral communities in eastern Australia: a qualitative biophysical model of factors regulating coral reefs. Coral Reefs 21:83-94

Harriott VJ, Smith SDA, Harrison PL (1994) Patterns of coral community structure of subtropical reef in the Solitary Islands Marine Reserve, eastern Australia. Mar Ecol Prog Ser 109:67-76
Hereu B, Zabala M, Linares C, Sala E (2004) Temporal and spatial variability in settlement of the sea urchin Paracentrotus lividus in the NW Mediterranean. Mar Biol 144: 1011-1018

Hillebrand H, Sommer U (1997) Response of epilithic microphytobenthos of the Western Baltic Sea to in situ experiments with nutrient enrichment. Mar Ecol Prog Ser 160: $35-46$

Holmes NJ, Harriott VJ, Banks SA (1997) Latitudinal variation in patterns of colonisation of cryptic calcareous marine organisms. Mar Ecol Prog Ser 155:103-113

Hoskin PR (1995) Organic enrichment and cryptofaunal communities: an experimental approach. MSc thesis, University of Plymouth

Hunt HL, Scheibling RE (1997) Role of early post-settlement mortality in recruitment of benthic marine invertebrates. Mar Ecol Prog Ser 155:269-301

Kay AM, Keough MJ (1981) Occupation of patches in the epifaunal communities on pier pilings and the bivalve Pinna bicolor at Edithburgh, South Australia. Oecologia 48:123-130

Kendall MA, Widdicombe S, Davey JT, Somerfield PJ, Austen MCV, Warwick RM (1996) The biogeography of islands: preliminary results from a comparative study of the isles of Scilly and Cornwall. J Mar Biol Assoc UK 76:219-222

Keough MJ (1983) Patterns of recruitment of sessile invertebrates in two subtidal habitats. J Exp Mar Biol Ecol 66: 213-245

Keough MJ, Butler AJ (2000) Temperate subtidal hard substrata. In: Kailola P (ed) The marine environment: technical annex 1. Great Barrier Reef Marine Park Authority, Townsville, p 37-52

Lemmens S (2003) Periphyton collectors as a tool to measure environmental performance of ocean outlets. Water Sci Technol 47:125-131

Martinez P, Navarrete SA (2002) Temporal and spatial variation in settlement of the gastropod Concholepas concholepas in natural and artificial substrata. J Mar Biol Assoc UK 82:257-264

Minitab (1996) Minitab statistical software, Version 13.1. Minitab, State College, PA

Mirto S, Danovaro R (2004) Meiofaunal colonisation on artificial substrates: a tool for biomonitoring the environmental quality on coastal marine systems. Mar Pollut Bull 48:919-926

Morrisey DJ, Howitt L, Underwood AJ, Stark JS (1992) Spatial variation in soft sediment benthos. Mar Ecol Prog Ser 81: 197-204

Myers AA, Southgate T (1980) Artificial substrates as a means of monitoring rocky shore cryptofauna. J Mar Biol Assoc UK 60:963-975

Norderhaug KM, Christie H, Rinde E (2002) Colonisation of kelp imitations by epiphyte and holdfast fauna; a study of mobility patterns. Mar Biol 141:965-973

Osman RW, Whitlatch RB (1998) Local control of recruitment in an epifaunal community and the consequences to colonization processes. Hydrobiologia 375:113-123

Pawlik JR, Butman CA, Starczak VR (1991) Hydrodynamic facilitation of gregarious settlement of a reef-building tube worm. Science 251:421-424

PRIMER (2001) PRIMER 5 for Windows, Version 5.2.4. PRIMER-E, Plymouth

Rodriguez SR, Ojeda FP, Inestrosa NC (1993) Settlement of benthic marine invertebrates. Mar Ecol Prog Ser 97: 193-207

Smith F, Witman JD (1999) Species diversity in subtidal landscapes: maintenance by physical processes and larval recruitment. Ecology 80:51-69 
Smith SDA (1996) The macrofaunal community of Ecklonia radiata holdfasts: variation associated with sediment regime, sponge cover and depth. Aust J Ecol 21:144-153

Smith SDA, Rule MJ (2002) Artificial substrata in a shallow sublittoral habitat: do they adequately represent natural habitats or the local species pool? J Exp Mar Biol Ecol 277:25-41

Smith SDA, Simpson RD (1991) Nearshore corals of the Coffs Harbour region, Mid-north coast New South Wales. Wetlands (Australia) 11:1-9

Sokal RR, Rohlf FJ (2001) Biometry. Freeman, New York

Stark JS (2000) The distribution and abundance of soft-sediment macrobenthos around Casey Station, east Antarc-

Editorial responsibility: Otto Kinne (Editor-in-Chief),

Oldendorf/Luhe, Germany tica. Polar Biol 23:840-850

Underwood AJ (1981) Techniques of analysis of variance in experimental marine biology and ecology. Oceanogr Mar Biol Annu Rev 19:513-605

Underwood AJ, Fairweather PG (1989) Supply-side ecology and benthic marine assemblages. Trends Ecol Evol 4: $16-20$

Watson DL, Barnes DKA (2004) Temporal and spatial components of variability in benthic recruitment, a 5-year temperate example. Mar Biol 145:201-214

Wiens JA (1989) Spatial scaling in ecology. Funct Ecol 3: 385-397

Submitted: September 9, 2004; Accepted: October 21, 2004

Proofs received from author(s): March 22, 2005 